\title{
The importance of physical activity and fitness programs in older people: a Systemic review
}

\author{
Marina Vukotic ${ }^{1}$ \\ 'University of Montenegro, Faculty for Sport and Physical Education, Niksic, Montenegro
}

\begin{abstract}
Several studies have dealt with costing different factors of physical fitness, and to investigate differences in physical fitness indicators depending on the size of the body mass index. Therefore, the purpose of this study is to research which would summarize potential factors of physical fitness in one place and their differences in fitness indicators depending on the size of the body mass index. The Google Scholar scientific database was used in this research, while all available materials were included in the analysis conducted by september 15, 2018. The field of search of the listed electronic database of original scientific papers referred to the application of various fitness programs in older people. The following keywords were used in the search for the listed database: "physical activity", "fitness", "older people" and "body mass index". Based on body mass index, respondents are in relation to sex, divided into groups: persons with normal body weight and persons with increased body weight. On the other hand, a significant difference was found in the indicators of functional fitness, depending on the body weight in favor of persons with normal body weight on subunits of women and men of older age.
\end{abstract}

Key words: physical activity, fitness, elderly and body mass index

\section{Uvod}

Savremeni način života uslovio je uvećanje populacije starijih osoba. Zbog te pojave istaknuta je potreba da se istražuju faktori čije djelovanje omogućava starijim osobama da same mogu da zadovoljavaju svoje životne potrebe (Kostić, Pantelić, Miletić, Uzunović, \& Aleksandrović, 2012). Bavljenje fižičkom aktivnošću preventivno djeluje pozitivno na zdravlje, a fizička aktivnost izuzetno je važna u starijoj životnoj dobi (Mitrovic, 2018; Kovacevic, 2018; Knezevic, 2018; Radulovic, 2018; Dragutinovic, 2018). Pozitivni psihofizički učinci po zdravlje mogu se očekivati u većoj mjeri ukoliko je vježbanje redovno, planirano i programirano. Fitness klubovi imaju jedinstvenu mogućnost da obezbijede vrijeme, kadar i prostor za fizičku aktivnost, i na taj način potpomognu unapređenju zdravlja ljudi starije životne dobi. Zdravlje treba posmatrati u širem smislu, a ne samo kao odsustvo bolesti (Marić, \& Marjanac, 2010; Bjelica, 2002, Bjelica, 2004; Bjelica, 2005; Bjelica, 2006a; Bjelica 2006b; Bjelica, 2013; Bjelica i Krivokapić, 2010; Bjelica i Krivokapić, 2011; Bjelica i Krivokapić, 2012; Bjelica i Fratric, 2011). Fizička aktivnost se ispoljava u mnogim čovjekovim svakodnevnim aktivnostima. Nivo fizičke aktivnosti je potreban da se ispune svakodnevni zahtijevi življenja, i da ostane nepromijenjen tokom života. U mlađem dobu fizička aktivnost je uglavnom veća od svakodnevnih potreba, ali se stalno smanjuje tokom procesa starenja. Na primer, mogućnost da se ustane iz sjedećeg položaja je smanjena posle 50. godine života, a nakon 80. godine ovaj zadatak postaje nemoguć za neke ljude. Snaga mišića opružača koljena kod normalno aktivnih muškaraca i žena se brzo smanjuje nakon 45.-50. godine (Radovanović \& Ignjatović, 2009; Krivokapic, 2015; Stankovic, 2009; Cordellat, Blasco-Lafarga, Monteagudo, Roldán, \& Velasco, 2016; Milosevic, Vukovic, Maksimovic, \& Matic, 2015; Sindik, Rendulić, Čorak, \& Lewis, 2014; Josephson \& Williams, 2017).

U radu (Malnar, Šterbik, Fužinac, Jerković \& Bobinac 2009) ispitani su stavovi prema fitness programima. O delova-

Correspondence:

Montenegro M.Vukotić

Gport University of Montenegro, Faculty for Sport and Physical Education, Narodne omladine bb, 81400 Niksic, Montenegro E-mail: marinavuk@ac.me 
nju fitness-a na poboljšanje njihovog zdravstvenog stanja, čak $83 \%$ ispitanika odgovorilo je pozitivno, $77 \%$ ispitanika izjasnilo se da vježbe pozitivno deluju na njihovo raspoloženje i koncentraciju, čak $90 \%$ ispitanika misli da su vježbe poboljšale njihovo držanje tijela. Primjena različitih grupnih fitness programa pokazala je značajne efekte u poboljšanju funkcionalnih i motoričkih sposobnosti (Mandarić, Sibinović, Mikalački, \& Stojiljković, 2011; Oreb, Matković, Vlašić, \& Kostić, 2007; Park, Park, Kwon, Yoon, \& Kim, 2003; Šebić, Šahat, Zuković, \& Lukić, 2012; Masanovic, Vukotic, Bjelica, \& Popovic, 2018; Popovic, Bjelica, Vukotic, \& Masanovic, 2018), kao i u promjeni kompozicije tijela kod ispitanika starije životne dobi (Donges, Duffield, \& Drinkwater, 2010; Stasiulis, Mockiene, Vizbaraite, \& Mockus, 2010; Popović, Bjelica, Mašanović, \& Vukotić, 2018; Mašanović, Popović, Bjelica, Vukotic, \& Zoric, 2018). Neki od značajnijih faktora su fizičke sposobnosti, koje se iskazuju parametrima fizičkog fitness-a i tjelesne mase (Kostić, Pantelić, Miletić, Uzunović \& Aleksandrović, 2012; Vukotic, 2010; Vukotic, 2011; Vukotic, 2018; Masanovic, 2009; Masanovic \& Vukasevic, 2009; Masanovic, Popovic, \& Bjelica, 2018; Popović, Mašanović, Molnar, \& Smajić, 2009; Vukasevic, Spaic, \& Masanovic, 2018; Vukasevic, Vukotic, \& Masanovic, 2018; Gusić, Popović, Molnar, Mašanović, \& Radaković, 2017; Masanovic, Popovic, \& Bjelica, 2018; Masanovic, 2018; Mašanović, Vukotić, Popović, \& Bjelica, 2018; Popovic, Akpinar, Jaksic, Matic, \& Bjelica, 2013; Popovic, Bjelica, Jaksic, \& Hadzic, 2014). Značajan broj istraživanja je procjenjivao različite faktore fizičke sposobnosti, sa ciljem da se istraže razlike u pokazateljima fizičkog fitness-a u zavisnosti od veličine indeksa tjelesne mase.

Stoga, glavni cilj ove studije i predstavlja istraživanje koje bi sumiralo na jednom mjestu potencijalne faktore fizičke sposobnosti, te njihove razlike u pokazateljima fitness-a u zavisnosti od veličine indeksa tjelesne mase.

\section{Metod}

Elektronska baza naučnih radova "Google Scholar" je korišćena u ovom istrazivanju, dok je sva dostpna građa do 15 septembar 2018. godine ušla u analizu koja je sprovedena. Oblast pretraživanja navedene elektroneske baze orginalnih naučnih radova se odnosila na primjenu različitih fitness programa kod osoba starije životne dobi. U pretraživanju gore navedene baze korišćene su sljedeće ključne rijeći: „fizička aktivnost“, „fitness“, „osobe starije životne dobi“ i ,indeks tjelesne mase“. Kasnije je izvršena klasifikacija naučnih studija. Autor je svaki pojedinačni rad pregledao i napravio selekciju prihvatljivih radova, dok je sve ostalo odbacio. Prema kriterijumima koju je ova studija predvidjela u okviru glavnog cilja, napravljena je uza selekcija radova koji su detaljno analizirani i prezentovani $\mathrm{u}$ ovom radu. Za sistemsku analizu radova koji su analizirani primijenjena je multivarijantna analiza MANOVA i univarijatna analiza ANOVA, na nivou značajnosti (Sig.) od 0.01 $(\mathrm{p} \leq .01)$. Radi utvrđivanja razlika između ispitanika kod dva rada primjenjen je Spearmanov korelacioni test i Skala ograničenja aktivnosti Groningena. Treba istaći da je ova sistematska analiza radova sprovedena u skladu sa principima „Preferred Reporting Items for Systematic Reviews and Meta-Analyses (PRISMA)“ (Moher i sar., 2009).

\section{Rezultati}

Inicijalno istrazivanje je uključilo 21 rada koji su sačinjavali osnovnu bazu podataka. Nakon svakog pregledanog rada isključeno je iz dalje analize 13 radova, jer se nijesu uklapali u cilj ovog istraživanja, dok je 8 radova ušlo u uzi izbor, koji su se detaljno sistemski analizirali. Glavni cilj na osnovu detaljne analize je da se istraže razlike u pokazateljima fizičkog fitness-a u zavisnosti od veličine indeksa tjelesne mase starih ljudi. Na osnovu indeksa tjelesne mase ispitanici su u odnosu na pol, podijeljeni na grupe: osobe sa normalnom tjelesnom težinom i osobe sa povećanom tjelesnom težinom. Sa druge strane, utvrđena je značajna razlika u pokazateljima funkcionalnog fitnesa u zavisnosti od tjelesne težine u korist osoba sa normalnom tjelesnom težinom na subuzorcima žena i muškaraca starije životne dobi. Analizirane studije ukazuju da ispitanici kojima je organizovana redovna fizička aktivnost odnosno različiti fitness porgrami imaju bolje razvijene motoričke i funkcionalne parametre koji im omogućavaju višu funkcionalnost i zdravlje.

Tabela 1. Sistemska analiza fizičke aktivnosti i fitness porgrama kod kod osoba starije životne dobi

\begin{tabular}{|c|c|c|c|c|}
\hline Autor(i) & $\begin{array}{c}\text { Cilj } \\
\text { Istraživanja }\end{array}$ & Uzorak ispitanika & $\begin{array}{c}\text { Statististička } \\
\text { analiza }\end{array}$ & Rezultati \\
\hline $\begin{array}{l}\text { Kostić i sar } \\
\text { (2011) }\end{array}$ & $\begin{array}{l}\text { Utvrditi pokazatelje } \\
\text { funkcionalnog fitnesa kod } \\
\text { telesne težine starih osoba }\end{array}$ & $\begin{array}{l}119 \text { ispitanika ,59 } \\
\text { muškaraca i } 60 \text { žena, } \\
\text { starosne dobi od } 65 \text { do } 70 \\
\text { godina iz Srbije (Južna i } \\
\text { Centralna Srbija) }\end{array}$ & ANOVA & $\begin{array}{l}\text { Utvrđene su statistički značajne } \\
\text { razlike u pokazateljima } \\
\text { funkcionalnog fitnesa u zavisnosti } \\
\text { od tjelesne težine u korist osoba sa } \\
\text { normalnom tjelesnom težinom }\end{array}$ \\
\hline $\begin{array}{l}\text { Kostić i sar } \\
(2012)\end{array}$ & $\begin{array}{l}\text { Utvrditi pokazatelje fizičkog } \\
\text { fitnesa u zavisnosti od } \\
\text { veličine BMI }\end{array}$ & $\begin{array}{l}1288 \text { ispitanika , } 594 \\
\text { muškarca i } 694 \text { žena } \\
\text { starosne dobi od } 60 \text { do } 80 \\
\text { godina iz Srbije } \\
\text { (Južna i Centralna Srbija) }\end{array}$ & ANOVA & $\begin{array}{l}\text { Utvrđene su statistički značajne } \\
\text { razlike u pokazateljima SFT između } \\
\text { subuzoraka prema BMI u korist } \\
\text { ispitanika sa normalnom tjelesnom } \\
\text { težinom. }\end{array}$ \\
\hline $\begin{array}{l}\text { Lepan } \\
\text { i Leutar } \\
\text { (2012) }\end{array}$ & $\begin{array}{l}\text { Utvrditi razlike } \\
\text { u funkcionalnim } \\
\text { sposobnostima između } \\
\text { starijih osoba koje se } \\
\text { redovito bave rekreativnim } \\
\text { tjelesnim aktivnostima i onih } \\
\text { koji to ne čine }\end{array}$ & $\begin{array}{l}342 \text { ispitanika, } 192 \\
\text { muškaraca i žena koje } \\
\text { se bave rekreativnim } \\
\text { vježbanjem i } 150 \\
\text { muškaraca i žena koji nisu } \\
\text { uključeni u rekreativno } \\
\text { vježbanje iz Hrvatske }\end{array}$ & MANOVA & $\begin{array}{l}\text { Utvrđene su statistički značajne } \\
\text { razlike razlike sociodemografskim } \\
\text { obilježjima ispitanika uključenih } \\
\text { u odnosu na neuključene u } \\
\text { rekreativne tjelesne aktivnosti }\end{array}$ \\
\hline
\end{tabular}


(continued from previous page)

\begin{tabular}{|c|c|c|c|c|}
\hline Autor(i) & $\begin{array}{c}\text { Cilj } \\
\text { Istraživanja }\end{array}$ & Uzorak ispitanika & $\begin{array}{c}\text { Statististička } \\
\text { analiza }\end{array}$ & Rezultati \\
\hline $\begin{array}{l}\text { Despot } \\
\text { Lučanin i } \\
\text { sar (2015) }\end{array}$ & $\begin{array}{l}\text { Utvrditi razlike BMI između } \\
\text { žena koje se bave fitnesom i } \\
\text { koje se ne bave fitnesom }\end{array}$ & $\begin{array}{l}21 \text { ispitanik, } 13 \text { žena koje } \\
\text { se aktivno bave fitnesom } \\
\text { od } 60 \text { godina i } 8 \text { žena } \\
\text { koje se ne bave fitnesom } \\
\text { starosne dobi } 70 \text { godina iz } \\
\text { Hrvatske }\end{array}$ & MANOVA & $\begin{array}{l}\text { Utvrđene su statistički značajne } \\
\text { razlike kod žena koje se bave } \\
\text { fitnesom, odnosno imaju bolje } \\
\text { razvijene motoričke i funkcionalne } \\
\text { parametre }\end{array}$ \\
\hline $\begin{array}{l}\text { Pokrajac } \\
\text { Bulian i sar } \\
(2016)\end{array}$ & $\begin{array}{l}\text { Utvrditi aerobni trening } \\
\text { na fiziološke sposobnosti i } \\
\text { kvalitetu života žena starije } \\
\text { životne dobi }\end{array}$ & $\begin{array}{l}15 \text { ispitanika, starije } \\
\text { životne dobi od } 65 \\
\text { godina,7aktivnih žena i } 8 \\
\text { naktivnih žena } \\
\text { iz Hrvatske }\end{array}$ & ANOVA & $\begin{array}{l}\text { Utvrđene su statistički značajne } \\
\text { razlike kod aktivnh žena koje su } \\
\text { imale poboljšanja u aerobnoj } \\
\text { izdržljivosti }\end{array}$ \\
\hline $\begin{array}{l}\text { Golubić } \\
\text { i Tomčić } \\
(2016)\end{array}$ & $\begin{array}{l}\text { Utvrditi razlike u fleksibilnosti } \\
4 \text { regije tijela kod žena } \\
\text { uključenih u grupne fitnes } \\
\text { programe u odnosu na žene } \\
\text { koje se ne bave nikakvom } \\
\text { tjelesnom aktivnošću. }\end{array}$ & $\begin{array}{l}60 \text { ispitanika, } 30 \text { žena koje } \\
\text { se aktivno bave fitnesom } \\
\text { i } 30 \text { žena koje se ne bave } \\
\text { fitnesom starosne dobi } 60 \\
\text { godina iz Hrvatske }\end{array}$ & MANOVA & $\begin{array}{l}\text { Utvrđene su statistički značajne } \\
\text { razlike kod žena koje se bave } \\
\text { fitnesom, odnosno imaju bolje } \\
\text { razvijene motoričke i funkcionalne } \\
\text { parametre }\end{array}$ \\
\hline
\end{tabular}

Sistemska analiza je pokazala da su osobe starije životne dobi koje su primjenjivale različite programe fitness-a imale bolji indeks tjelesne mase, od osoba koje se ne bave rekreativnim vježbanjem. Što je indeks više izvan okvira urednih vrednosti, to je veći rizik od obolevanja od raznih srčanih bolesti (Bjelica, 2007), dijabetesa i povišenog krvnog pritiska kod osoba starije životne dobi (Kostić, Uzunović, Pantelić, \& Đurašković, 2011; Kostić, Pantelić, Miletić, Uzunović, \& Aleksandrović, 2012; Lepan \& Leutar, 2012; Despot Lučanin, Černja, Lopižić, \& Rudolfi, 2015; Pokrajac-Bulian, Miletić, Juretić, \& Lopižić, 2016; Golubić \& Tomčić, 2016).

\section{Diskusija}

Studija sa područja Srbije na osnovu anketnih upitnika ispitanika koji žive u sopstvenim domaćinstvima u gradovima i selima Centralne, Istočne i Južne Srbije, ističe različitost uticaja faktora čije djelovanje omogućava starijim osobama da same mogu da zadovoljavaju svoje životne potrebe. Razlika u pokazateljima funkcionalnog fitnesa u zavisnosti od tjelesne težine je u korist osoba sa normalnom tjelesnom težinom na subuzorcima žena i muškaraca. (Kostić, Uzunović, Pantelić, \& Đurašković, 2011; Kostić, Pantelić, Miletić, Uzunović, \& Aleksandrović, 2012). Pozitivni psihofizički učinci po zdravlje mogu se očekivati u većoj mjeri ukoliko je vježbanje redovno sistemski planirano i programirano. Neke procjene pokazuju da u Hrvatskoj samo $0.6 \%$ osoba starijih od 65 godina redovno vježba u organiziranim grupama (Lepan i Leutar, 2012; Sekulic, 2018).

Tabela 2. Sistemska analiza fizičke aktivnosti i fitness porgrama kod kod osoba starije životne dobi

\begin{tabular}{lllll}
\hline Autor(i) & \multicolumn{1}{c}{$\begin{array}{c}\text { Cilj } \\
\text { istraživanja }\end{array}$} & \multicolumn{1}{c}{ Uzorak ispitanika } & Statistička analiza & \multicolumn{1}{c}{ Rezultati } \\
\hline $\begin{array}{l}\text { Gilson Luis } \\
\text { i sar }\end{array}$ & $\begin{array}{l}\text { Utvrditi evaluaciju indeksa } \\
\text { telesne mase, procenta } \\
\text { telesne masti, kratkog } \\
\text { fizičkog učinka baterije } \\
\text { i nivoa obrazovanja } \\
\text { učesnika }\end{array}$ & $\begin{array}{l}195 \text { ispitanika žena i } \\
\text { muškaraca sarosne dobi } \\
60 \text { i 79 godina, iz Brazila }\end{array}$ & $\begin{array}{l}\text { Spearmanovog } \\
\text { korelacionog testa }\end{array}$ & $\begin{array}{l}\text { Utvrđene su statistički značajne } \\
\text { razlike procentu telesne masti, } \\
\text { kratkog fizičkog učinka baterije } \\
\text { (SPPB) i nivoa obrazovanja } \\
\text { učesnika }\end{array}$ \\
$\begin{array}{l}\text { Meg i sar } \\
(2010)\end{array}$ & $\begin{array}{l}\text { Utvrditi predviđenu } \\
\text { masu skeletnih mišića } \\
\text { procenjenu pomoću } \\
\text { jednačine analize }\end{array}$ & $\begin{array}{l}\text { 275 ispitanika, 148 } \\
\text { muškaraca, 127 žena } \\
\text { starosne dobi od 65 } \\
\text { godina, Tajpeja (Kina) }\end{array}$ & $\begin{array}{l}\text { Skale ograničenja } \\
\text { aktivnosti } \\
\text { Groningena }\end{array}$ & $\begin{array}{l}\text { Utvrđene su statistički } \\
\text { značajnerazlike u masi } \\
\text { skeletnih mišića }\end{array}$ \\
\hline
\end{tabular}

Istraživanje koje je sporivedeno u Brazilu imalo je deskriptivni, kvantitativni i poprečni presek. Dobijena je različitost u evaluacijji indeksa tjelesne mase i procenta tjelesne masti. Sa druge strane dobijena je različitost rezultata kratkog učinka fitness bateriije testova i nivoa obrazovanja učesnika (Gilson, Greice, Daiane, \& Geraldine, 2017). Interesanto je da su Brazilci imali veći porcenat masti i indeks tjelesne mase u odnosu na stanovnike Centralne, Istočne i Južne Srbije. Sa druge strane studija u Kini je pokazala uporednu analizu fizičke kativnosti, mišićne snage kod ispitanika iz Tajpeja. Interesantno je da indeks telesne mase nije pokazao velike razlike unutar is- pitavane populacije (Meng-Yueh, Hsu-Ko, \& Ying-Tai, 2010). $\mathrm{Na}$ osnovu svega navedenog može se istaći da je malo poznato o primjerima fitness programa i njihovim dozranjem opterećenjima kod ljudi starije životne dobi, vjerojatno zbog velikih individualnih razlika. Redovno vježbanje jedno je od najprirodnijih metoda za očuvanje sposobnosti organizma, sprečavanje i ublažavanje razvoja promjena kod ljudi starije životne dobi i bolesti koji nastaju starenjem organizma. Očuvanje vitalnih funkcija organizma je osnovni uslov za dobro zdravlje, a utiče na raspoloženje, osjećaja korisnosti, optimizma i kvalitet života. 
Na osnovu sistemske analize ove studije može se istaći, da je autor ovog rada došao do malog broja naučnih orginalnih radova koji su se bavili istraživanjem ljudi starije životne dobi. Prema kriterijumima izvršena je klasifikacija naučnih studija, i to iz: Srbije, Hrvatske, Brazila i Kine. U elektronskoj bazi naučnih radova"Google Scholar" nije pronađenja nijedna studija iz Crne Gore koja se bavila ovom tematikom. Sto dovodi do zaključka, da treba sprovesti jednu studiju u Crnoj Gori koja bi se sastojala od anketnih upitnika da bi se vidjelo koliko se crnogorska populacija starije životne dobi rekreativno bavi fizičkim aktivnostima i odraditi testiranje antropometirjskih varijabli, te na osnovu dobijenih rezultata bi mogli uporediti sa stanovnistvo Crne Gore sa stanovnistvom iz Srebije, Hrvatske, Brazila i Kine, i izvrsiti sistemsku analizu na osnovu indeksa tjelsene mase.

\section{Acknowledgements}

There are no acknowledgements.

\section{Conflict of Interest}

The authors declare that there are no conflicts of interest.

Received: 13 September 2018 | Accepted: 15 October 2018 | Published: 29 October 2018

\section{References}

Bjelica, D. (2002). Opšti pojmovi sportskog treninga: (skraćena verzija). Podgorica: Crnogorska sportska akademija.

Bjelica, D. (2004). Uticaj sportskog treninga na antropomotoričke sposobnosti: (fudbalskih kadeta Crne Gore). Podgorica: Crnogorska sportska akademija.

Bjelica, D. (2005). Sistematizacija sportskih disciplina i sportski trening. Podgorica: Crnogorska sportska akademija.

Bjelica, D. (2006a). Sportski trening. Podgorica: Crnogorska sportska akademija.

Bjelica, D. (2006b). Teorijske osnove tjelesnog i zdrastvenog obrazovanja. Podgorica: Crnogorska sportska akademija.

Bjelica, D. (2007). Teorijske osnove tjelesnog i zdravstvenog obrazovanja. Podgorica:

Bjelica, D. (2013). Teorija sportskog treninga. Podgorica: Univerzitet Crne Gore.

Bjelica, D., \& Fratrić, F. (2011). Sportski trening: teorija, metodika i dijagnostika. Nikšić: Fakultet za sport i fizičko vaspitanje.

Bjelica, D., i Krivokapić D. (2012). Uticaj fizičkog vježbanja na psihomotorne funkcije starijih osoba. Zbornik radova Druge međunarodne konferencije Sportske nauke i zdravlje, Banja Luka: Panaevropski univerzitet Aperion, 191-6.

Bjelica, D., i Krivokapić, D. (2010). Teorijske osnove fizičke kulture. Nikšić: Fakultet za sport i fizičko vaspitanje Univerziteta Crne Gore.

Bjelica, D., i Krivokapić, D. (2011). Teorija igre. Nikšić: Fakultet za sport i fizičko vaspitanje Univerziteta Crne Gore.

Cordellat, A., Blasco-Lafarga, C., Monteagudo, P., Roldán, A., \& Velasco, M. (2016). Balance changes in trained and untrained elderly undergoing a five-months multicomponent training program. Sport Mont, 14(3), 25-9.

Despot Lučanin, J., Černja, I., Lopižić, J. \& Rudolfi, N. (2015). Differences in physical abilities between active and non-active elderly females. Psihologija starenja pogled u budućnost, 23. Godišnja konferencija hrvatskih psihologa, (20-25), Zagreb: Hrvatsko psihološko društvo.

Donges, C. E., Duffield, R., \& Drinkwater, E. J. (2010). Effects of resistance or aerobic exercise training on interleukin-6, C-reactive protein, and body composition. Medicine andScience in Sport and Exercise, 42 (2), 304-413.

Dragutinovic, K. (2018). Self-reported and objectively measured physical activity of elderly women in Podgorica. Journal of Anthropology of Sport and Physical Education, 2(3), 155-8. doi: 10.26773/jaspe.180727

Gilson. L., Greice. T., Daiane, B., \& Geraldine, A. (2017). Oxidative damage to DNA in independent living elderly persons and their correlations with sociodemographic, anthropometric, and functional parameters 2016 . $J$ Appl Physiol, 122(5), 1238-48

Golubić, A., \& Tomčić, J. (2016). Razlike u razini fleksibilnosti kod zena uključenih u grupne fitnss pograme u odnosu na eaktivne žene. 25. Ljetnja škola kineziologa republike Hrvatske (192-197), Split: Hrvatski kineziološki savez.

Gusić, M., Popović, S., Molnar, S., Mašanović, B., \& Radaković, M. (2017) Sport-Specific Morphology Profile: Differences in Anthropometric
Characteristics among Elite Soccer and Handball Players. Sport Mont, 15(1),3-6.

Josephson, M. D., \& Williams, J. G. (2017). Functional-strengthening: A pilot study on balance control improvement in community-dwelling older adults. Montenegrin Journal of Sports Science and Medicine, 6(2), 75-8. doi: 10.26773/mjssm.2017.09.010

Knezevic, M. (2018). Self-reported and objectively measured physical activity of elderly womens from Bar and Podgorica. Journal of Anthropology of Sport and Physical Education, 2(3), 39-42. doi: 10.26773/jaspe.180707

Kostić, R., Pantelić, S., Miletić, Đ., Uzunović S., \& Aleksandrović, M. (2012). Pokazatelji fizičkog fitness-a starijih ljudi u zavisnosti od vrijednosti indeksa tjelesne mase. Physical Education and Sport, 10(1), 1-11.

Kostić, R., Uzunović S., Pantelić, S., \& Đurašković, R. (2011). Fizička aktivnost i fitness komponente starih ljudi. Physical Education and Sport, 9(2), 16171.

Kovacevic, M. (2018). Self-reported and objectively measured physical activity of elderly mans from Bar. Journal of Anthropology of Sport and Physical Education, 2(3), 79-83. doi: 10.26773/jaspe.180714

Krivokapic, D. (2015). Adapted swimming training focused on improvement of psychophysical status od elderly people. Sport Mont, 13(43-44-45), 307-12.

Lepan, Ž., \& Leutar, Z. (2012) .The importance of physical activity for older adults. Socijalna ekologija, 21(2), 203-23.

Malnar, D., Šterbik, K., Fužinac, S.A., Jerković, R., Bobinac, D. (2009). Pilates tehnika vježbanja. Medicina, 43 (3), 241-5.

Mandarić, S., Sibinović, A., Mikalački, M., \& Stojiljković, S. (2011). The effects of theprogram HI-Low aerobics on morphological characteristics and functional ability students in the eight grade. Journal of Sports science and Health, 1 (1), 18-23.

Marić, M. \& Marjanac, A. (2010). Efekti primene modela vežbanja sa tegovima i tegovimana apsolutnu snagu žena. Međunarodni naučno-stručni skup studenata sporta i fizičkogvaspitanja "Mladi o sportskoj nauci i struci“(93-102). Novi Sad: Fakultet sporta i fizičko vaspitanja Univerziteta u Novom Sadu.

Masanovic, B. (2009). Differences of anthropometrical status on top level handball players and non sportsmen. Sport Mont, 6(18-19-20), 569-75.

Masanovic, B. (2018). Comparative study of anthropometric measurement and body composition between junior basketball and volleyball players from Serbian national league. Sport Mont, 16(3), 19-24. doi: 10.26773/smj.181004

Masanovic, B., \& Vukasevic, V. (2009). Differences of anthropometrical status on basketball and handball players in junior stature. Sport Mont, 6(1819-20), 576-82.

Masanovic, B., Popovic, S., \& Bjelica, D. (2018a). Comparative Study of Anthropometric Measurement and Body Composition Between Junior Soccer and Volleyball Players From National League. In Book of Abstracts 15th International Scientific Conference on Transformation Process in Sport "Sport Performance" (58), Podgorica: Montenegrin Sports Academy.

Masanovic, B., Popovic, S., \& Bjelica, D. (2018b). Comparative Study of Anthropometric Measurement and Body Composition Between Junior Soccer and Volleyball Players From National League. In Book of Abstracts 15th International Scientific Conference on Transformation Process in Sport "Sport Performance" (58), Podgorica: Montenegrin Sports Academy.

Mašanović, B., Popović, S., Bjelica, D., Vukotic, M., \& Zoric, G. (2018). The effects of physical activity on depressive symptoms among elderly people: a systematic review. In Proceedings World Congress of Performance Analysis of Sport XII (423). Opatija: International Society of Performance Analysis of Sport.

Masanovic, B., Vukotic, M., Bjelica, D., \& Popovic, S. (2018). Describing Physical Activity Profile of Older Montenegrin Males Using the International Physical Activity Questionnaire (IPAQ). In Book of Abstracts 15th International Scientific Conference on Transformation Process in Sport "Sport Performance" (61), Podgorica: Montenegrin Sports Academy.

Mašanović, B., Vukotić, M., Popović, S., \& Bjelica, D. (2018). Comparative study of anthropometric measurement and body composition between junior basketball and volleyball players from Serbian national league. In Book of Abstract World Congress of Performance Analysis of Sport XII. Zagreb: Faculti of Kinesiology.

Meng-Yueh, C., Hsu-Ko, K., \&Ying-Tai, W. (2010). Sarcopenia, Cardiopulmonary Fitness, and Physical Physical Disability in Community-Dwelling Elderly People. Physical Therapy, 90(9), 1277-87.

Milosevic, Z., Vukovic, J., Maksimovic, N., \& Matic, R. (2015). Eurobarometer - physical activity of inhabitants of the ap vojvodina. Sport Mont, 13(4344-45), 7-16.

Mitrovic, M. (2018). Self-reported and objectively measured physical activity of males from 50 to 69 years old. Journal of Anthropology of Sport and Physical Education, 2(2), 99-101. doi: 10.26773/jaspe.180417

Moher, D., Liberati, A., Tetzlaff, J., Altman, D.G., \& PRISMA Group. (2009). 
Preferred reporting items for systematic reviews and meta-analyses: the prisma statement. PLoS Medicine, 6(7),e1000097.

Oreb, G., Matković, B., Vlašić, J., \& Kostić, R. (2007). The structure of the functional abilities of the dancers. Croatian sports herald, 9 (1), 16-23.

Park, S. K., Park, J. H, Kwon, Y. C., Yoon, M. S., \& Kim, C. S. (2003). The effects of longterm aerobic exercise on maximal oxygen consumption, left ventricular function and serum lipids in elderly women. Journal of Physiological Anthropology and applied Human Science, 22 (1), 11-7.

Pokrajac-Bulian, A., Miletić, I., Juretić, J., \& Lopižić, J. (2016). Učinci 24-tjednog aerobnog treninga na fiziološke sposobnosti i kvalitetu života žena starije životne dobi. Psihologija u prevenciji poremećaja i očuvanju zdravlja. 24. godišnja konferencija hrvatskih psihologa (87-93), Zagreb: Hrvatsko psihološko društvo.

Popovic, S., Akpinar, S., Jaksic, D., Matic, R., \& Bjelica, D. (2013). Comparative Study of Anthropometric Measurement and Body Composition between Elite Soccer and Basketball Players. International Journal of Morphology, 31(2), 461-7.

Popović, S., Bjelica, D., Mašanović, B., \& Vukotić, M. (2018). Describing physical activity profi le of young Montenegrin females using the international physical activity questionnaire (IPAQ). In Proceedings World Congress of Performance Analysis of Sport XII (344). Opatija: International Society of Performance Analysis of Sport.

Popovic, S., Bjelica, D., Vukotic, M., \& Masanovic, B. (2018). Describing Physical Activity Profile of Older Montenegrin Females Using the Internationa Physical Activity Questionnaire (IPAQ). In Book of Abstracts 15th International Scientific Conference on Transformation Process in Sport "Sport Performance" (60-61), Podgorica: Montenegrin Sports Academy.

Popović, S., Mašanović, B., Molnar, S., \& Smajić, M. (2009). Determining Body Composition of Top Level Athletes. Teme, 33(4), 1534-49.

Popovic. S., Bjelica, D., Jaksic, D., \& Hadzic, R. (2014). Comparative Study of Anthropometric Measurement and Body Composition between Elite Soccer and Volleyball Players. International Journal of Morphology, 32(1), 267-74.

Radovanović, D. i lgnjatović, A. (2009). Fiziološke osnove treninga sile i snage.
Niš: Fakultet sporta I fizičkog vaspitanja.

Radulovic, J. (2018). Self-reported and objectively measured physical activity of males from 50 to 69 years old. Journal of Anthropology of Sport and Physical Education, 2(3), 123-6. doi: 10.26773/jaspe.180721

Sekulic, N. (2018). Report of the 5th International Congress of Nutritionists. Journal of Anthropology of Sport and Physical Education, 2(1), 57-60. doi: 10.26773/jaspe.180110

Sharkey, B. \& Gaskill, S. (2008). Vežbanje i zdravlje. Beograd: Data status.

Sindik, J., Rendulić, D., Čorak, S., \& Lewis, A. (2014). Analysis of the Relevant Factors of Retaining Women in Judo. Montenegrin Journal of Sports Science and Medicine, 3(2), 23-31.

Stankovic, V. (2009). The influence of phisical educatin on devolpement of abilities of elderly schoolchildren. Sport Mont, 6(18-19-20), 474-9.

Stasiulis, A., Mockiene, A., Vizbaraite, D., \& Mockus, P. (2010). Aerobic exercise-induced changes in body composition and blood lipids in young women. Medicine, 46 (2), 129-34.

Vukasevic, V., Spaic, S., \& Masanovic, B. (2018). Comparative study of anthropometric measurement and body composition between the basketball player first and second league in Montenegro. Journal of Anthropology of Sport and Physical Education, 2(3), 61-5. doi: 10.26773/jaspe.180711

Vukasevic, V., Vukotic, M., \& Masanovic, B. (2018). Comparative study of morphological characteristics and body composition between basketball players from second leagues in Montenegro and Serbia. Journal of Anthropology of Sport and Physical Education, 2(3), 21-5. doi: 10.26773/ jaspe. 180704

Vukotić, M. (2010). Nivo morfoloških karakteristika, motoričkih i funkcionalnih sposobnosti sportista različitog sportskog usmjerenja. Neobjavljena magistarska teza. Nikšić: Fakultet za sport i fizičko vaspitanje.

Vukotić, M. (2011). Differences of anthropometric characteristic and motor abilities of different sport orientation. Sport Mont, 9(28-29-30), 112-8.

Vukotic, M. (2018). Comparative analysis of antropmtric indicators of sportisis of different soprts guidance. In Book of Abstracts 15th International Scientific Conference on Transformation Process in Sport "Sport Performance" (75-76), Podgorica: Montenegrin Sports Academy. 